DIW BERLIN

Discussion

Papers
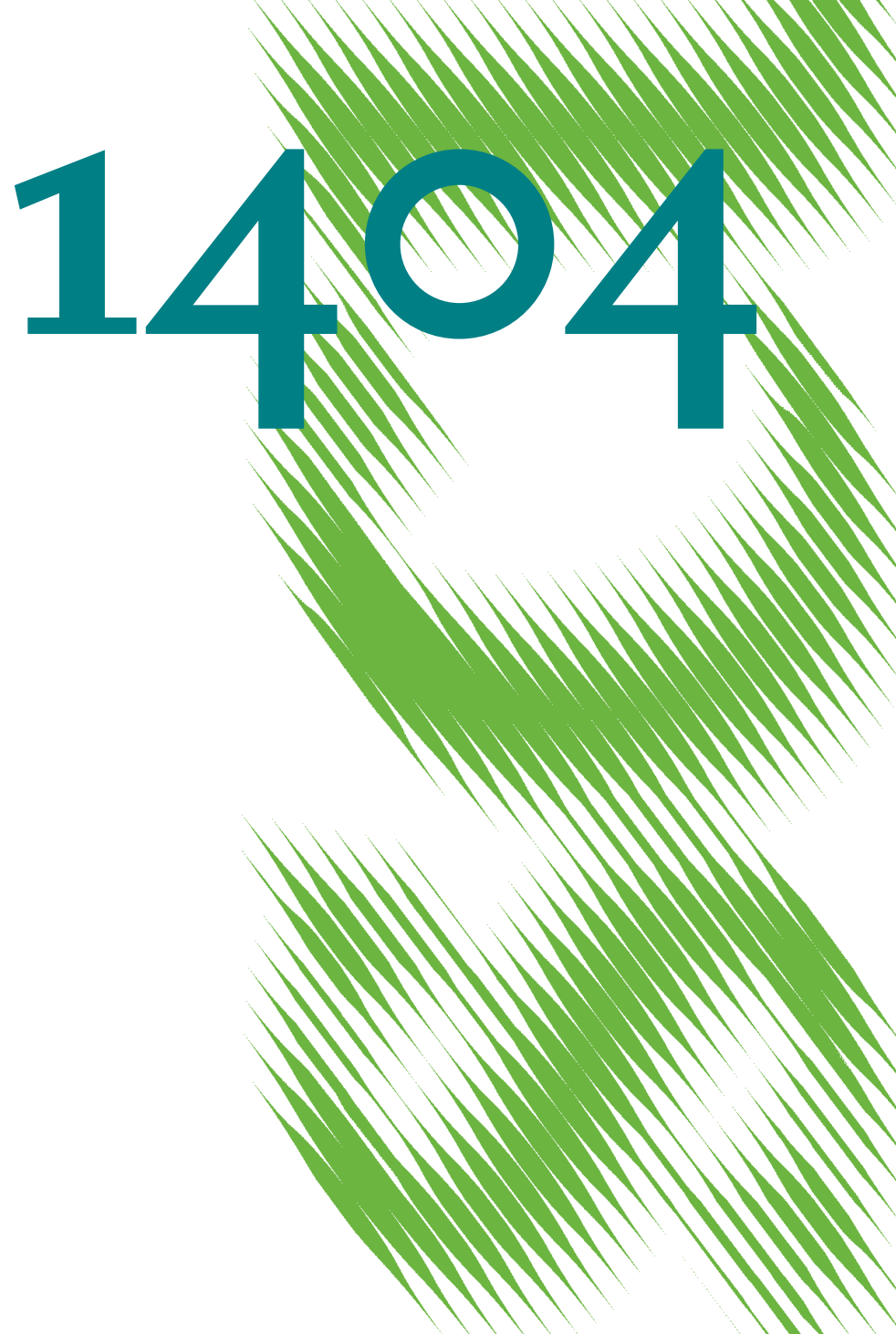

Is There Still a Case for Merchant

Interconnectors? Insights from an Analysis of Welfare and Distributional Aspects of Options for Network Expansion in the Baltic Sea Region 
Opinions expressed in this paper are those of the author(s) and do not necessarily reflect views of the institute.

IMPRESSUM

(C) DIW Berlin, 2014

DIW Berlin

German Institute for Economic Research

Mohrenstr. 58

10117 Berlin

Tel. +49 (30) $89789-0$

Fax +49 (30) $89789-200$

http://www.diw.de

ISSN electronic edition 1619-4535

Papers can be downloaded free of charge from the DIW Berlin website:

http://www.diw.de/discussionpapers

Discussion Papers of DIW Berlin are indexed in RePEc and SSRN:

http://ideas.repec.org/s/diw/diwwpp.html

http://www.ssrn.com/link/DIW-Berlin-German-Inst-Econ-Res.html 


\title{
Is there still a Case for Merchant Interconnectors? Insights from an Analysis of Welfare and Distributional Aspects of Options for Network Expansion in the Baltic Sea Region
}

\author{
Clemens Gerbaulet*†' Alexander Weber*
}

August 2014

\begin{abstract}
Despite the ongoing appetite of financial investors for merchant investments into the European electricity network, the EC is reluctant to approve such undertakings, thus implicitly favoring regulated investments. Based on a two-level model, we analyze the impact of profit-maximizing merchant transmission investment as compared to welfare-maximizing regulated transmission investment. We apply the model to the Baltic Sea region, which has in the past been subject to rapid interconnector development and still would benefit from increased interconnection. We obtain stable results indicating that merchant investment may well contribute to overall welfare, but at the same time, "the merchant takes it all", i.e. in many cases merchant profits are close to the overall efficiency gain, and sometimes even higher. These results underline that that distributional aspects, besides mere welfare arguments should be taken into account when analyzing the impact of merchant transmission investment.
\end{abstract}

JEL Codes: L51, L94, D30, D60

Keywords: Merchant, Regulated, Transmission Expansion, MPEC

${ }^{*}$ Berlin University of Technology, Workgroup for Infrastructure Policy (WIP), Straße des 17. Juni 135, 10623 Berlin. \{cfg,aw\}@wip.tu-berlin.de.

${ }^{\dagger}$ German Institute for Economic Research (DIW Berlin), Department of Energy, Transportation, Environment, Mohrenstraße 58, 10117 Berlin. 


\section{Contents}

1. Introduction 3

2. Model 5

2.1. The Regulator's Optimization Problem. . . . . . . . . . . . . . . . . 5

2.2. The Merchant's Optimization Problem . . . . . . . . . . . . . . . 7

2.3. Further Assumptions . . . . . . . . . . . . . . . . . . . . 8

2.4. Model Implementation . . . . . . . . . . . . . . . . . . . . . . . . . 8

3. Model Application to the Baltic Sea Region 9

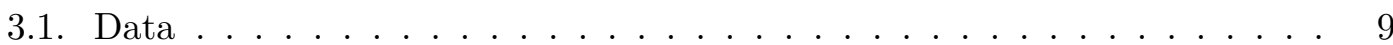

3.1.1. Generation . . . . . . . . . . . . . . . . 9

3.1.2. Network . . . . . . . . . . . . . . . . . . . . . . . 11

3.1.3. Load . . . . . . . . . . . . . . . . . . . . . . . 11

3.1.4. Investment Cost . . . . . . . . . . . . . . . . . . . 12

3.1.5. Reference Hours . . . . . . . . . . . . . . . . . . . . 13

3.2. Scenarios . . . . . . . . . . . . . . . . . . . . 13

3.3. The Merchant's Investment Choices . . . . . . . . . . . . . . . . . . 13

4. Results and Discussion 14

4.1. The Stackelberg Case . . . . . . . . . . . . . . . . . . . . . . . . . . . . . . 14

4.2. Relaxing the Stackelberg Assumption . . . . . . . . . . . . . . . . . 15

\begin{tabular}{lr}
\hline 5. Conclusion & 20
\end{tabular}

\begin{tabular}{ll}
\hline A. Nomenclature & 26
\end{tabular}

B. Background on Merchant Interconnectors in Europe 27

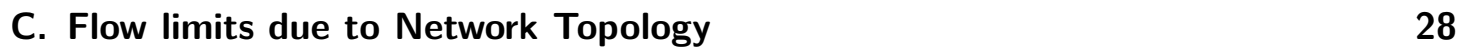

D. Identification of Reference Hours 30

$\begin{array}{ll}\text { E. Tables } & 31\end{array}$ 


\section{Introduction}

Current European electricity policy, driven by market integration and decarbonisation targets, sets a strong impetus for expanding transmission networks: European transmission companies identified in their 2012 plans (ENTSO-E, 2012a, p. 70) investment needs of roughly $€ 100$ bn by 2022 . Although most of the investment can be expected to be regulated, merchant transmission investments ${ }^{1}$ are possible within the current legal and institutional framework, but need to be approved on a case-by-case basis by the European Commission. In light of the large investment needs some see an increasing importance of this option (Cuomo and Glachant, 2012, Mann, 2013). What, however, remains unclear is the role merchant transmission investment can or should play in this context: While at first glance the difference between profit-maximizing "merchant" transmission investment and (supposed-to-be) welfare-maximizing investment seems to be easy to analyze, this is not so much the case once further aspects are taken into account.

Although, in theory, merchant transmission lines might be an option, Joskow and Tirole (2005) find (by extending theoretical models) that in practice problems of asset specificity, lumpiness and market power pose serious problems to the desirability of merchant interconnectors. In a similar line of reasoning, Kuijlaars and Zwart (2003) and Knops and De Jong (2005) underline the problems of underinvestment (as compared to the welfare optimal solution). As a remedy to the under-investment problem, Brunekreeft (2005) suggests (regulatory) "capacity checks." From a modeling perspective, e.g. Egerer et al. (2013); Doorman and Frøystad (2013) find, for cases of the North and Baltic Seas, that those transmission expansion alternatives leading to the highest welfare contribution cannot be financed by earnings from arbitrage (on which merchant transmission projects would rely) and thus substantiate the theoretical considerations of under-investment and simultaneously call for putting "capacity checks" into context. Further, Joskow (2005) and Turvey (2006) highlight that market driven interconnector investment may overlook reliability aspects while focusing on wholesale-driven economic aspects.

The above findings, which seem to deliver strong arguments against merchant transmission expansion, need to be qualified: Regulated arrangements may not always be possible. One reason for this is that if technology is (new and) risky, the regulator may not be able to credibly commit to not expropriate the upside and would thus prevent the investment. Gans and King (2004) argue that in such a case, temporary "access holidays" (i.e. an exemption from TPA rules) and thus an exemption from monopoly regulation may help to overcome the investment barrier as the commitment to partially cease regulation could be given more credibly. In addition to enabling investments, they also highlight that such "access holidays" may also be used to set incentives for a quicker delivery of the investment. Beyond the risk-argument literature (Brunekreeft, 2004, Kristiansen and Rosellón, 2010, Teusch et al., 2012) suggests two more relevant reasons: first, regulators of the affected jurisdictions might not want to agree on the project as redistributive effects

${ }^{1}$ Merchant lines must be financed from the earnings of arbitrage between electricity prices in the two interconnected jurisdictions, while regulated lines are financed by fees raised via grid tariffs overseen by a regulator. 
could be unwanted and, second, vertically integrated transmission companies could be hindered by the group's management as the project could interfere with the utilities' generation/retail positions.

The former, inter-jurisdictional coordination aspect is highlighted by e.g. Gately (1974); Nylund (2012); Tangerås (2012); Buijs and Belmans (2012); Egerer et al. (2013) using both analytic and simulation models: They confirm that coordination of transmission investment can be highly complex. Concerning the latter argument, de Hauteclocque and Rious (2011) emphasize that in addition to TSO subsidiary companies, which historically took on the role, generator companies could also play an important role as merchant investors in Europe.

Further, Littlechild (2012) generally argues in favor of merchant interconnectors on the basis of case evidence - in those he finds that merchant investment was superior to what regulators attempted to do.

In the EU, however, merchant interconnectors have not yet played a big role, as of August 2014, only three such projects have been realized and Cuomo and Glachant (2012) find that the European Commission has, over time, become more and more reluctant to grant exemptions from regulation. An outline of the history of merchant interconnector investment is presented in Annex B. Yet, there are still numerous $2^{2}$ proponents of merchant investments and hence, the issue cannot be considered "dead".

Therefore, the objective of this paper is to understand the impact, both in terms of welfare and distribution, of "market"-driven transmission investment as compared to both socially optimal (regulated) transmission investment and the absence of such investment in the European context. We study the problem in the example of the Baltic Sea region, where systems of different energy planning paradigms provide a case for increased interconnection. Our contribution is in both the modeling and the results:

- For the modeling, we use a bi-level set up to take into account the interdependence between the strategic capacity choices of merchant investors and the welfaremaximizing choices left to the regulated part of the sector. We use a full representation of the extra high voltage (EHV) grid of the region studied, allowing for endogenous, line-sharp transmission expansion while taking into account directcurrent load flow (DCLF) principles, bidding-zone-based unit-commitment and price formation. We do further use a k-means approach to select reference hours to keep the problem computationally tractable. To our knowledge, such a level of detail has not previously been used to study the impact of merchant investments.

- We find that, somehow contrary to the more stylized analyses cited above, welfare contribution of merchant investment is roughly between 80 and $90 \%$ of the maximum improvement possible, but that this welfare increase does mainly accrue to the merchant investor as a rent. In some cases, redistribution is so severe that the merchant's rent is higher than his welfare contribution. Therefore, the argument that merchant investment may be an option if regulated transmission investment is not possible seems to be weakened: From a perspective of distributional aspects,

\footnotetext{
${ }^{2}$ cf. Mann (2013)
} 
policy-makers might not want to pursue a solution which does not bring any benefit to established actors or even reduces their welfare.

The remainder of this paper is structured as follows: Next, section 2 outlines the respective optimization problems of merchants and regulators and the model applications used in this paper. Section 3 describes the application and relevant input parameters. The results of the application are discussed in section 4 . Section 5 concludes.

\section{Model}

The regulator in our model seeks to minimize overall cost of the electricity system by controlling power plant dispatch and deciding on AC transmission expansion. Power plant dispatch follows a zonal approach, as currently implemented in Europe; however, if cheaper than transmission expansion, deviations from the zonal merit order list are allowed.

Merchants that plan and build cross-border lines have a different objective. Their goal is to maximize profit (i.e. their congestion rent), which is the congestion revenue minus the line investment cost. Congestion revenue accrues when prices between two connected zones differ and further trade between these zones is limited due to upstream grid congestion or full utilization of the cross-border line. The price difference on the merchant's line multiplied by the amount of energy transmitted is the congestion revenue. As (operational) withholding of capacity is not an option within the EU legislation, we do not consider this alternative 3

We model the interaction between the two parties as a two-stage game where the merchant's optimization problem is solved taking into account the reaction of the regulator and assume that there is only one merchant investor. This implies that the merchant is first-mover in this game, i.e. the Stackelberg leader. Although this set-up seems to be very preconditioning, it yields interesting results, which remain stable when we relax the Stackelberg assumption later on.

\subsection{The Regulator's Optimization Problem}

The regulator's objective is to minimize system cost, by coordinating both dispatch and network expansion. Although the regulator has a global view, he may not be able conduct transmission investment between all systems which limits his powers and thus mimics the inability to coordinate cross-border investment.

Power plant dispatch is conducted on the basis of bidding zones, i.e. transmission is not priced within zones. Transmission is modeled following DCLF principles (Schweppe et al. 1988: Stigler and Todem, 2005; Leuthold et al., 2012). As transmission expansion problems in electricity networks are typically non-convex, we apply a linear relaxation provided by Taylor and Hover (2011). There, the flow in the existing network strictly follows DCLF

\footnotetext{
${ }^{3}$ Yet, Brunekreeft and Newbery (2006) argue that allowing capacity withholding during operation in the exemption period could reduce problems of under-investment.
} 
principles mentioned above, whereas the flows through the endogenously added AC lines must be approximated. Equations (1)-12 show the regulator's optimization problem.

$$
\min \sum_{s, b z, t} C_{s} \times q_{s, b z, t}+\sum_{l} I_{l r} \times \exp _{l r}
$$

s.t.

[generation; $\forall s, b z, t$ ]

$$
0 \geq q_{s, b z, t}-\sum_{b z:(n \in b z)} Q_{s, n}^{\max }
$$

[nodal balance; $\forall n, t]$

$$
\begin{aligned}
0= & +D_{n, t}-\sum_{s, b z:(n \in b z)}\left[Q_{s, n}^{\max } \times \frac{q_{s, b z, t}}{\sum_{n n \in b z} Q_{s, n n}^{\max }}\right] \\
& -\sum_{l m}\left[I n c_{l m, n} \times \zeta_{l m, t}\right] \\
& -\sum_{l r}\left[I n c_{l r, n} \times\left(\zeta_{l r, t}+B_{l r} \times \operatorname{Exp}_{l r} \times \sum_{n n} \delta_{n n, t} \times I n c_{l r, n n}\right)\right]
\end{aligned}
$$

[DCLF, slack bus; $\forall n, t]$

$$
0=\delta_{n, t} \times \text { Slack }_{n}
$$

[HVDC-Limits; $\forall l m, t]$

$$
\begin{aligned}
& 0 \geq \zeta_{l m, t}-\exp _{l m}-E x p 0_{l m} \\
& 0 \geq-\zeta_{l m, t}-\exp _{l m}-\operatorname{Exp}_{l m}
\end{aligned}
$$

$[$ DCLF-Limits; $\forall l r, t]$

$$
\begin{aligned}
& 0 \geq B_{l r} \times \sum_{n} \delta_{n, t} \times I n c_{l r, n}-\min \left\{M_{l r}^{\zeta}, F_{l r}^{\max }\right\} \\
& 0 \geq-B_{l r} \times \sum_{n} \delta_{n, t} \times \operatorname{Inc}_{l r, n}-\min \left\{M_{l r}^{\zeta}, F_{l r}^{\max }\right\}
\end{aligned}
$$

[DCLF expansion flow upper limits on abs flow; $\forall l r, t]$

$$
\begin{aligned}
& 0 \geq-\zeta_{l r, t}-\min \left\{M_{l r}^{\zeta}, F_{l r}^{\max }\right\} \times \exp _{l r} \\
& 0 \geq \zeta_{l r, t}-\min \left\{M_{l r}^{\zeta}, F_{l r}^{\max }\right\} \times \exp _{l r}
\end{aligned}
$$


[DCLF expansion flow lower limits on abs flow; $\forall l r, t]$

$$
\begin{aligned}
0 \geq & B_{l r} \times \sum_{n} I n c_{l r, n} \times \delta_{n, t} \times \overline{\operatorname{Exp}}_{l r}-\zeta_{l r, t} \\
& -\min \left\{M_{l r}^{\zeta}, F_{l r}^{\max }\right\} \times\left[\overline{\operatorname{Exp}}_{l r}-\exp _{l r}\right] \\
0 \geq & -B_{l r} \times \sum_{n} I n c_{l r, n} \times \delta_{n, t} \times \overline{\operatorname{Exp}}_{l r}+\zeta_{l r, t} \\
& -\min \left\{M_{l r}^{\zeta}, F_{l r}^{\max }\right\} \times\left[\overline{\operatorname{Exp}}_{l r}-\exp _{l r}\right]
\end{aligned}
$$

The overall cost is determined in the argument of the minimization in (1). It consists of the generation cost as well as the grid expansion cost. (2) constrains maximum electricity generation $q_{s, b z, t}$ per technology and bidding zone. The network is represented by an incidence matrix $I n c_{l, n}$, assigning line end points to nodes $n$. Lines $l$ are divided into regulated AC lines $l r \in l$ and merchant DC lines $l m \in l$. Voltage angles are expressed by $\delta_{n, t}$, relative line susceptance is denoted as $B_{l}$. Nodal balance is enforced by (3), where nodal generation, demand, flows of existing $\mathrm{AC}$ lines (angle difference times $B_{l}$ ), including expansion $\left(\zeta_{l r, t}\right)$, and DC line flows $\zeta_{l m, t}$ are taken into account. For each synchronous area, a slack node is defined through (4) to ensure a unique solution during the optimization. For controllable flows on merchant lines, conditions (5, 6) impose the respective flow limits: $E x p 0_{l m}$ denotes existing capacity in MW, $\exp _{l m}$ is the endogenously determined capacity expansion. For the AC lines, (7, 8) impose the relevant thermal limits onto the phase angle differences. Here, $F_{l r}^{\max }$ denotes the thermal limit of existing line $l r$, whereas $M_{l r}^{\zeta}$ shows the lower bound given by parallel paths. $M_{l}^{\zeta}$ is determined applying a Dijkstra-Algorithm (1959) onto the electrical network. See Annex C for a detailed explanation. AC transmission expansion is applied by an expansion factor exp $p_{l r}$, where a value of 0 means no expansion and a value of 1 determines doubling the existing lines' capacity. Upper and lower limits due to this expansion are expressed by $(9,10)$ and 11,12 . Whereas the former two equations do impose maximum limits on the flow through the endogenously added lines, the latter two equations impose minimum limits on the flow based on maximum line expansion factors $\overline{\operatorname{Exp}}_{l r}$ and are due to Taylor and Hover (2011).

\subsection{The Merchant's Optimization Problem}

The merchant tries to optimize his profit, which consists of the congestion rent on a line minus the expenditure needed to build the corresponding lines. The merchant's profit maximization problem is shown in (13)- 15 .

$$
\max _{\operatorname{explm}}\left(\sum_{l m} \exp _{l m}\left[\frac{\sum_{t} \zeta_{l m, t} \times p D_{l m, t}}{\operatorname{Exp}_{l m}+\exp _{l m}}-I_{l m}\right]\right)
$$


s.t.

$$
\begin{array}{cc}
p D_{l m, t}=\sum_{\begin{array}{c}
\forall n, n n: \\
I n c_{l m, n}=1, \\
I n c_{l m, n n}=-1
\end{array}}\left(p_{n, t}-p_{n n, t}\right) & \forall l m, t \\
\exp _{l m} \geq 0 & \forall l m
\end{array}
$$

The profit of the merchant is determined in (13), where the flow is multiplied by the price difference and subtracted by the investment cost of lines. In case the merchant expands previously existing lines, he is only eligible to receive the share of the congestion rents attributable to his capacity addition. Both the flow on regulated and merchant lines is set by the regulator. The price $p_{n, t}$ and the price difference between nodes $p D_{l m, t}$ in (14) are a result of the regulator's optimization. The price can be defined in two ways: It can either be the dual variable of the zonal balance or the marginal cost of the most expensive power plant dispatched in the respective bidding zone. In the former case, the price would be the zonal average of the duals of the nodal balance in (3), giving the cost of an additional MWh to be delivered in that area. This price would include the cost of regulated network expansion, which would be attributed to the importing zone. As opposed to this, just taking the marginal cost of the most expensive power plant dispatched in the bidding area, would neglect long-run costs of network expansion and any marginal flow effects. In the following we will call the different approaches to be reflecting long-run marginal cost (LRMC) and short-run marginal cost (SRMC), respectively.

\subsection{Further Assumptions}

Investments in specific lines are restricted to a single actor. The regulator can invest in $\mathrm{AC}$ lines while the merchant can invest in DC cross-border lines only, i.e.

$$
\operatorname{lm} \cap \operatorname{lr}=\emptyset .
$$

\subsection{Model Implementation}

The two-stage model set-up translates into an MPEC (mathematical problem with equilibrium constraints). For sufficiently small problems, MPECs can be solved by expressing the follower's problem(s) in their Karush-Kuhn-Tucker (KKT) form. The computational difficulty lies then in quickly solving the complementarity problem (Gabriel and Leuthold 2010), but often this can be done efficiently with help of disjunctive constraints, such that the MPEC can be solved as a mixed integer problem (MIP), using a large range of solvers available (Leuthold et al. 2012).

As the MPEC of this paper (when applied to the real system of the Baltic Sea Region) is too complex for the traditional, integrated approach, the solution space for the merchant's investment decision is discretized and each element is evaluated by solving the corresponding lower-level linear problem (LP). Then, the profit maximizing choice is selected in a consecutive step by evaluating all lower-level outcomes. Although it could be argued that this is not precise, because slightly different figures would result if the 
discretization would not be applied, real HVDC projects actually come in steps, with some minor exceptions for smaller projects. Further, this approach also eliminates the difficulties that the bi-linearity in 13 would pose to integrated solution approaches.

\section{Model Application to the Baltic Sea Region}

We apply the model to the electrical System of the Baltic Sea Neighboring countries (Denmark, Estonia, Finland, Germany, Latvia, Lithuania, Poland, and Sweden), taking into account bidding zones in Sweden (SvK, 2011), and publicly available plans for both generation and network through 2020. An overview of the network and bidding zones is given in Figure 1 .

We essentially apply information from ENTSO-E's (2012a) 10-Year Network Development Plan ("TYNDP", including the "Scenario Outlook and Adequacy Forecast", SOAF, ENTSO-E, 2012c), assuming Scenario "B" 2020, the "Baltic Energy Market Interconnection Plan" (BEMIP, EC, 2009a, 2012, CESI, 2009). Further, we use diverse sources on generation, load and networks as set out in section 3.1 .

In addition to that, we need to choose a set of both distinct reference hours considered by the model and the possible investment choices of the merchant in order to keep the model computationally feasible. These adjustments are tackled in sections 3.1 .5 and 3.3 . respectively.

To conduct our analysis, we compare the merchant solution against two extreme scenarios in terms of costs and rents accruing to the different parties (generators, regulated transmission, consumers, merchant investors). The two additional scenarios are (i) the Fully Planned case, where we assume a cost-minimizing, central regulator who conducts plant dispatch and network expansion, both for AC and DC lines, and (ii) the AC Only case, where no DC expansion is possible, but plant dispatch and AC investment is done in a cost-minimizing way. The overall three different scenarios compared against each other are introduced in section 3.2 .

\subsection{Data}

\subsubsection{Generation}

Generation technologies considered are both dispatchable and non-dispatchable (i.e. variable renewable energy sources; VRE) types. For dispatchable generation, power plant data from PLATTS (2011) is used as a basis for the spatial distribution of technologies within the electricity grid. For VRE generation, locations and distribution of installations are determined using NUTS-2 potential maps from ESPON (2010, pp. 226), except for Germany, where detailed data on installation sites is available from the TSOs. The resulting distribution of generation capacities is, subsequently, scaled according to SOAFdata using a brown-field approach. For dispatchable generation, fuel and carbon prices were taken, where applicable, from the "Current Policies Scenario" of IEA's World Energy Outlook (International Energy Agency and Organisation for Economic Co-operation and Development, 2011, pp. 64, 66), in line with the assumptions of the Baltic Regional 


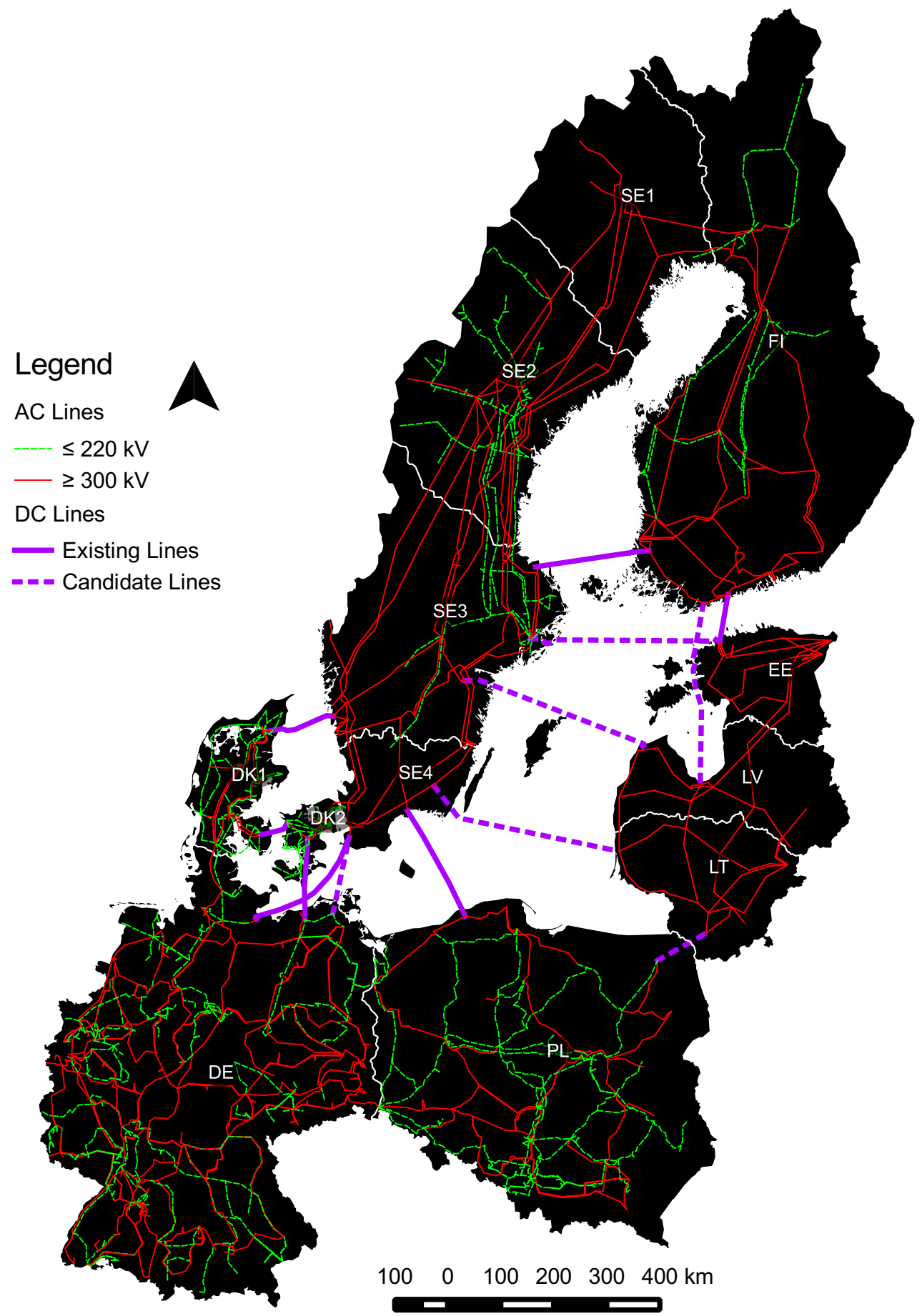

Figure 1: Model region and network

Projection in TM Baltic 93, Source: Own depiction using shapefile data from Eurostat, SvK, ENTSO-E. 
Investment Plan of the 2012 TYNDP (ENTSO-E, 2012b, p. 38). Other values are chosen manually, except for Hydro (reservoirs), where no costs are assumed, but maximal energy is restricted to an average historical full-load factor of 0.5 , which was derived from ENTSO-E data. Availabilities are taken from a TSO assessment (50Hertz et al., 2013a, p. 32) and set to 0.9 for the thermal technologies that are not covered by that report. Pumped storage is neglected due to both the limited significance in our application and the difficulty of pumped storage modeling when using reference hours (cf. 3.1.5). An overview of dispatchable generation technologies considered is given in Table 1 .

VRE feed-in time-series is taken from the respective TSOs (50Hertz, Amprion, Augstprieguma tīkls, Elering, Energinet.DK, Litgrid, Svenska Kraftnät, TenneT, TransnetBW). This data is not available for Finland and Poland, thus the time series are interpolated from neighboring countries. The time series are then scaled to historical full-load hours for the different technologies and split over the nodes using the installation data (see above for the procedure) on a NUTS-2 level. If more than one node per NUTS-2 region was present, VRE feed-in was split evenly among them. As VRE was considered as non-dispatchable, it was subtracted from load to obtain a "residual" load curve per node.

\subsubsection{Network}

The starting grid that is assumed for 2020 in this application is based on the ENTSOE grid map (ENTSO-E, 2011) from 2010 and includes all mid-term TYNDP projects with completion dates between 2012 and 2016 (ENTSO-E, 2012a) as well. Although this paper's setting is in 2020, we assume slight delays in the completion of the grid development projects. Therefore the long-term projects that - according to the TYNDP should be built between 2017 and 2022 are not part of the starting grid. The number of AC lines considered totals to an amount of 1,281. Further to that, we include the Ambergate project listed in the Baltic Energy Market Interconnection Plan (BEMIP), connecting SE3 (Norrköping) and LV (Ventspils) (EC, 2009a; CESI, 2009, p. 10), as well as the recently announced Hansa PowerBridge project (Svenska Kraftnät and 50Hertz, 2014 ) between Germany and Sweden (connecting nodes are not yet known, we assume DE-Lüdershagen and SE-Kruseberg), as well as two hypothetical connections between Estonia and Sweden (EE-Haku and SE-Stockholm), and Finland and Latvia (FI-Inkoo and LV-Bisuciems).

In order to take into account the (N-1)-criterion of network operation, all AC lines are allowed to use only $70 \%$ of their nominal capacity, which is taken from (50Hertz et al. 2012 p. 102).

\subsubsection{Load}

Hourly load data is taken from ENTSO-E (2013) for 2012 and is scaled up to annual consumption levels of the SOAF's B-2020 scenario. Consumption levels are displayed in Table 2. Load is considered inelastic as reliable data are neither available nor could they be expected to be beneficial to the study. Load-shedding is allowed on a zonal basis, at a price of $2,000 € / \mathrm{MWh}$. 
Table 1: Dispatchable Generation Technologies: Efficiencies and Availabilities.

\begin{tabular}{|c|c|c|}
\hline Technology & Efficiency & Availability \\
\hline Hydro & - & 1 \\
Biomass & - & 0.9 \\
Lignite & - & 0.935 \\
Nuclear & - & 0.945 \\
Waste & - & 0.9 \\
Coal & 0.38 & 0.94 \\
Combined Cycle Gas Turbine & 0.47 & 0.977 \\
Combined Cycle Oil Turbine & 0.47 & 0.977 \\
Gas Steam Turbine & 0.38 & 0.977 \\
Oil Steam Turbine & 0.38 & 0.977 \\
Open Cycle Gas Turbine & 0.3 & 0.977 \\
Open Cycle Oil Turbine & 0.3 & 0.977 \\
\hline
\end{tabular}

Source: (50Hertz et al., 2013a, p. 32). When efficiency is not given, marginal generation cost are chosen discretely.

Table 2: Consumption levels

\begin{tabular}{|c|c|}
\hline Country & Consumption $[\mathrm{GWh} / \mathrm{a}]$ \\
\hline FI & 98300 \\
$\mathrm{DE}$ & 562200 \\
$\mathrm{DK}$ & 37110 \\
$\mathrm{EE}$ & 11391 \\
$\mathrm{LT}$ & 12560 \\
$\mathrm{LV}$ & 8458 \\
$\mathrm{PL}$ & 178494 \\
$\mathrm{SE}$ & 154000 \\
\hline
\end{tabular}

Source: ENTSO-E $[2012 \mathrm{c})$.

\subsubsection{Investment Cost}

Investment costs are adapted from data provided in the German network development plan (50Hertz et al. 2013b, p. 364). For reasons of tractability, no differentiation between the different EHV voltage levels are made, and DC installations are assumed to have identical per MW, per km cost for both subsea and onshore overhead installations. The data are given in Table 3. For DC installations, a recovery period of 20 years is assumed and for AC installations 30 years are taken into account. Discounting and, thus, financing cost are neglected but could without greater difficulty be added. 
Table 3: Grid investment cost. Source: (50Hertz et al., 2013b, p. 364)

\begin{tabular}{|c|c|c|}
\hline Grid Technology & Cost & Unit \\
\hline AC overhead line (2 systems) & 1.4 & $\mathrm{M} € / \mathrm{km}$ \\
DC line & 700 & $€ /(\mathrm{MW} \times \mathrm{km})$ \\
DC converter station & 130 & $€ / \mathrm{kW}$ \\
\hline
\end{tabular}

\subsubsection{Reference Hours}

Due to the computational complexity, we restrict our analysis to 8 reference hours. To select those, we apply a k-Means clustering approach in order to identify hours that best represent typical situations of load and VRE-infeed. See Annex D for details. We also account for the size of the respective clusters by introducing a weight factor that corrects for the "duration" of the reference hour.

\subsection{Scenarios}

We compare three scenarios to show the effect of different grid expansion approaches:

1. AC Only: No new HVDC lines are allowed; only a fully coordinated regulator may expand AC-lines between adjacent countries,

2. Stackelberg: The Stackelberg-game is modeled; Merchant is first-mover for HVDC lines; regulator is follower for AC connections and dispatch,

3. Fully Planned: All lines are expanded on a cost-minimizing basis by the regulator.

The rationale behind this set-up is to identify how well the second best solution of allowing merchants to build HVDC lines performs, both in terms of total cost and allocation of rents to producers, consumers, and merchants. For the calculation of rents, it is necessary to make assumptions for both the consumer's willingness-to-pay (WTP) and the pricing mechanism. For the former, we assume a WTP of $180 € / \mathrm{MWh}$, making sure this limit is never hit. For the pricing mechanism, we evaluate pricing based both on the long-run and the short-run marginal cost (LRMC/SRMC) as defined in 2.2 .

\subsection{The Merchant's Investment Choices}

As noted in 2.4. we discretize the merchant's action space in order to overcome the computational difficulties of bi-linearity and of the integrated solution of the MPEC, i.e. reformulating the lower level into its KKT form. We choose the following approach to select the investment choices available to the merchant investor:

1. First, we select the non-zero HVDC expansion decisions of the fully planned case that are equal or greater than $250 \mathrm{MW}$. These are the candidate lines that the merchant investor is entitled to invest in. 
2. For the candidate lines, we allow the merchant to invest in steps of $250 \mathrm{MW}$, from 0 to four $250 \mathrm{MW}$ steps beyond the fully planned extension level, and including the exact value of the fully planned level.

The discretization results in 62208 investment alternatives. The overall MPEC was solved on a computing cluster, using GUROBI and each of the LPs consumed about 43 seconds of CPU time.

\section{Results and Discussion}

In this section, we present and discuss our results. First (section 4.1), we present the outcomes of the Stackelberg game, where the merchant investor is the leader of the two-stage game. Second, in section 4.2, we relax the Stackelberg assumption by taking a look at the larger set of investment options, most still profitable from a merchant perspective, but less extreme than the Stackelberg optimum.

\subsection{The Stackelberg Case}

We compare outcomes of the Stackelberg scenarios against the AC Only and Fully Planned scenarios. The DC transmission investment decisions in the Stackelberg cases (both under LRMC and SRMC pricing) and in the Fully Planned scenario are presented in Table 4 The AC Only scenario is left out since no investment into additional DC transmission capacity takes place here.

Interestingly, while under LRMC pricing, a significant underinvestment - just about $36 \%$ of the DC transmission expenditure in the 'optimal' case - is observable, the merchant invests even more than in the Fully Planned case when SRMC pricing is applied. This latter observation is somewhat counterintuitive to the underinvestment critique brought forward against merchant investments in the literature. In course of this section, we will discuss this observation in more detail. The economic implications of the merchant's choices, under both pricing schemes, are presented in Figure 24 rents and costs for each actor are stacked group-wise, illustrating changes in welfare, distribution and efficiency. The costs for the different cases are given in 6 .

The analysis of rents \& costs yields some interesting insights:

- While we see that under LRMC pricing the merchant's investment expenditure is relatively low, and nearly 3 times higher under SRMC pricing, the welfare gains are in both cases fairly equal: These amount to roughly $80-90 \%$ of what could have been gained under the Fully Planned solution.

- Still, despite this not-so-small welfare gain, in the LRMC case, it nearly fully accrues to the merchant investor as a rent, while under SRMC pricing the merchant profit is

\footnotetext{
${ }^{4}$ To improve the presentation, consumer and producer rents are reduced by their respective minima, and generation cost by half of their minimum so that absolute changes remain observable. Further, it is important to note that the congestion rents of AC lines and existing DC lines are combined (light blue) and congestion rents accruing to new DC transmission investments are separate (yellow).
} 
Table 4: Expansion of transmission lines in the Stackelberg-LRMC, Stackelberg-SRMC and Fully Planned cases. For existing lines, only the additional expansion is given, no reduction of existing capacity was considered.

\begin{tabular}{|c|c|c|c|c|}
\hline & & \multicolumn{3}{|c|}{ Line Expansion [MW] } \\
\hline & Line & $\begin{array}{l}\text { Stackelberg- } \\
\end{array}$ & $\begin{array}{l}\text { Stackelberg- } \\
\text { SRMC }\end{array}$ & $\begin{array}{l}\text { Fully } \\
\text { Planned }\end{array}$ \\
\hline \multirow{7}{*}{ 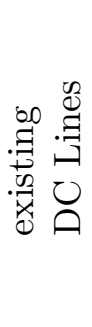 } & DE-DK2 (Kontek) & - & - & - \\
\hline & DE-SE4 (Baltic Cable) & - & - & - \\
\hline & DK1-DK2 (Storebælt) & - & - & - \\
\hline & DK1-SE3 (Konti-Skan) & - & - & $81^{a}$ \\
\hline & FI-EE (Estlink) & 500 & - & 1602 \\
\hline & FI-SE3 (Fenno-Skan) & - & - & - \\
\hline & PL-SE4 (SwePol) & - & 1750 & 940 \\
\hline \multirow{6}{*}{ 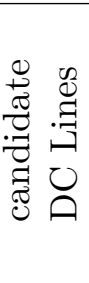 } & DE-SE4 (Hansa PowerBridge) & - & 1750 & 969 \\
\hline & EE-SE3 & - & - & - \\
\hline & FI-LV & - & - & - \\
\hline & LT-PL (LitPol) & 250 & 1250 & 583 \\
\hline & LT-SE4 (NordBalt) & - & - & - \\
\hline & LV-SE3 (Ambergate) & 544 & - & 544 \\
\hline \multicolumn{2}{|c|}{ Total DC Line Investment costs $[\mathrm{mn} €]$} & 195.80 & 551.28 & 547.98 \\
\hline
\end{tabular}

${ }^{a}$ These expansion decisions were neglected for the determination of the merchant's action space, because they are $\leq 250 \mathrm{MW}$, cf. section 3.3

considerably higher than the overall welfare gain. This means that in the latter case, all other actors do in aggregate lose rents as compared to the $A C$ Only scenario. An overview of overall welfare contribution and profit share reaped by the merchant is given in Table 5 .

- Although generation cost decreases from AC Only, over Stackelberg to Fully Planned, the same is not true for AC line investment costs. AC line investment cost are highest in the LRMC-Stackelberg scenario, somewhat corresponding with the low DC expansion level. This implies that the Stackelberg investor's choices may potentially increase the cost of the cost-minimizing investment alternatives of the regulator. This is interesting, as it illustrates that a merchant Stackelberg investor may also increase parts of the total system cost beyond the level of the AC Only / Fully Planned scenarios.

\subsection{Relaxing the Stackelberg Assumption}

Although a rigorous analysis of more "competitive" merchant investment, taking into account sequential/simultaneous set-ups, is beyond the scope of this paper and requires 


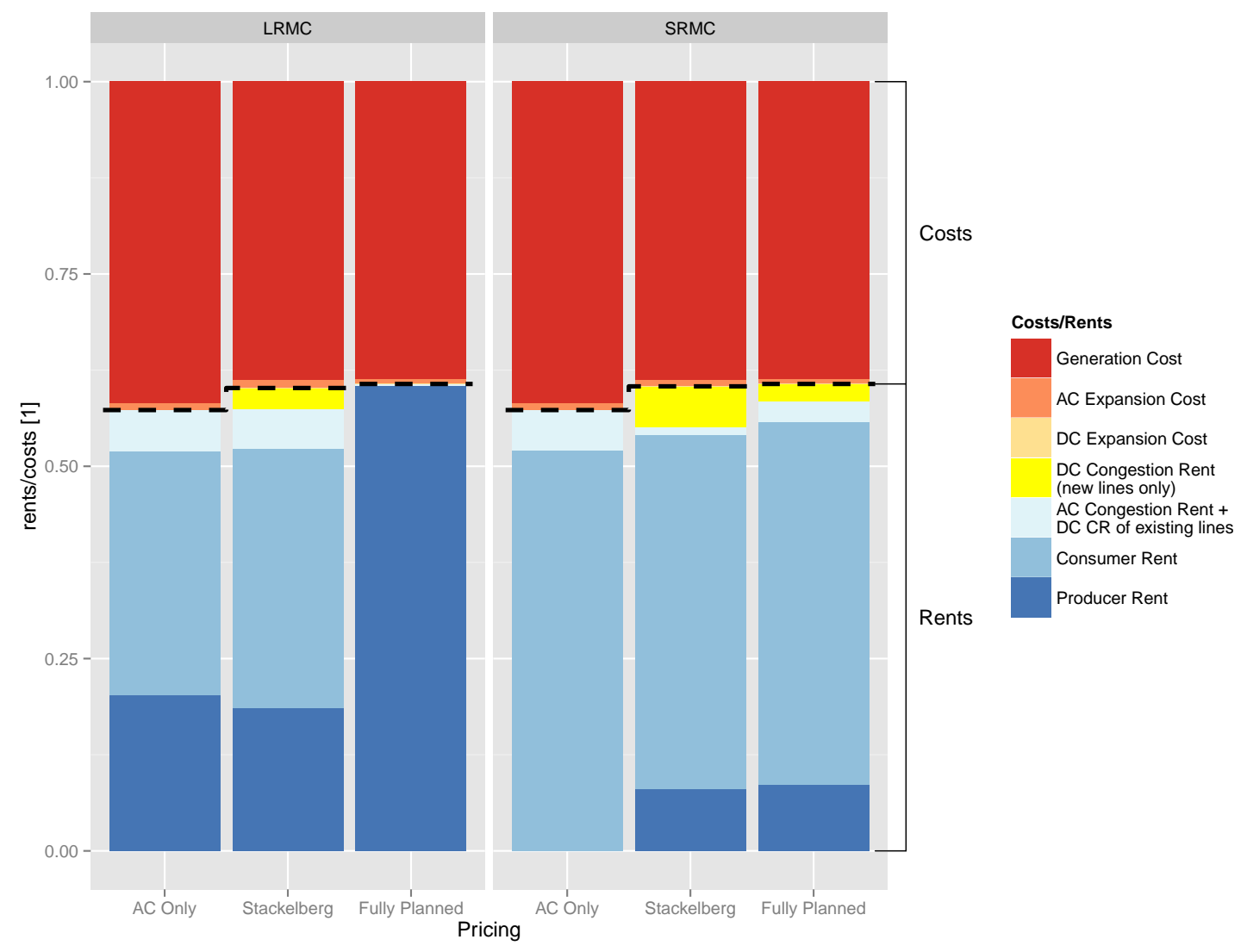

Figure 2: Costs and Rents in all three cases, LRMC and SRMC prices. Source: Own Calculations.

complex assumptions, looking at the remaining 62208 calculated DC investment alternatives allows for some observations.

To do so, we analyze the contribution to overall welfare and the change of the sum of generator, regulated transmission and consumer rents against the AC Only and Fully Planned cases. As we collect our observations from the evaluations of the discretized merchant action space only, the Fully Planned benchmark used differs very slightly from Stackelberg benchmark as small investments $(\leq 250 \mathrm{MW})$ are neglected (cf. 3.3).

In Figures 3 and 4 , we analyze overall welfare contribution (as before, relative to maximum, Fully-Planned cases, and normalized) and merchant profit of the respective investment possibilities, averaged over pre-defined intervals along unit profit and unit investment expenditure to improve clarity. What can be seen is that profit maximization sets an incentive to invest the same amount of money less efficiently. This is interesting as it shows that under-investment is not the only caveat regarding unregulated transmission investment: There can also be an incentive to invest inefficiently in terms of network structure, i.e. market prices (as modeled here) do not alone suffice to direct transmission investment to where it is most needed. 


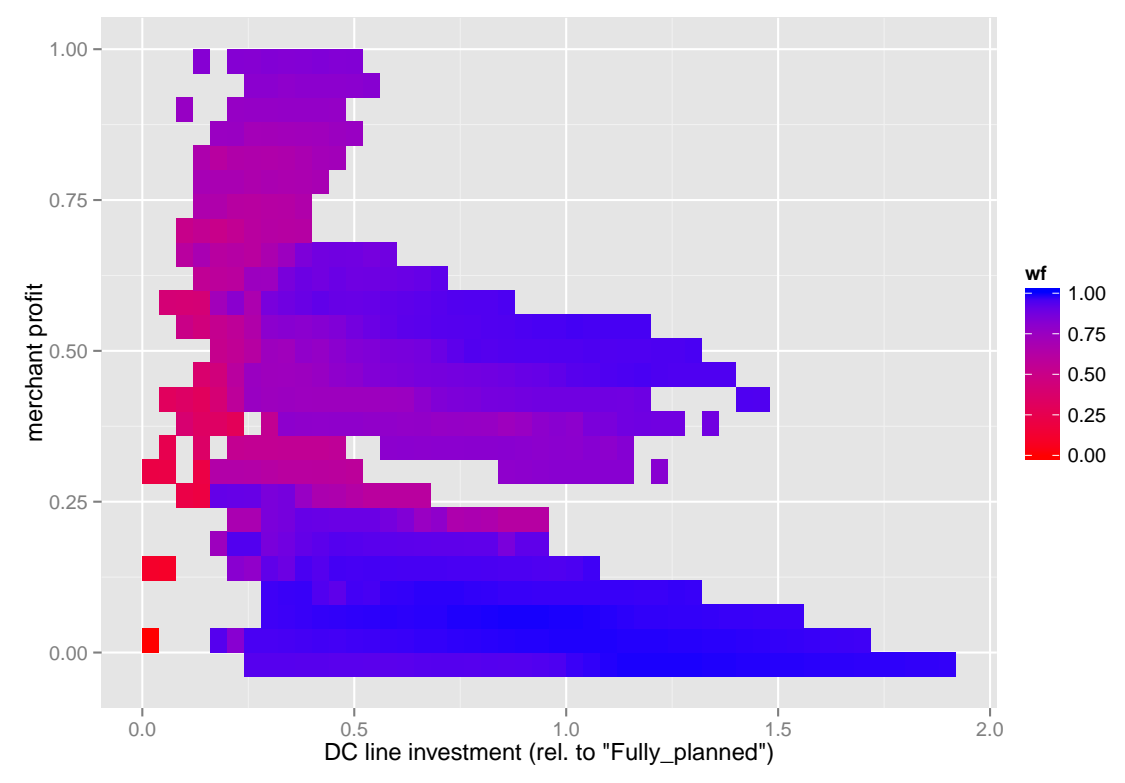

Figure 3: Unit welfare contribution (wf) and unit merchant profit for different investment choices under LRMC pricing.

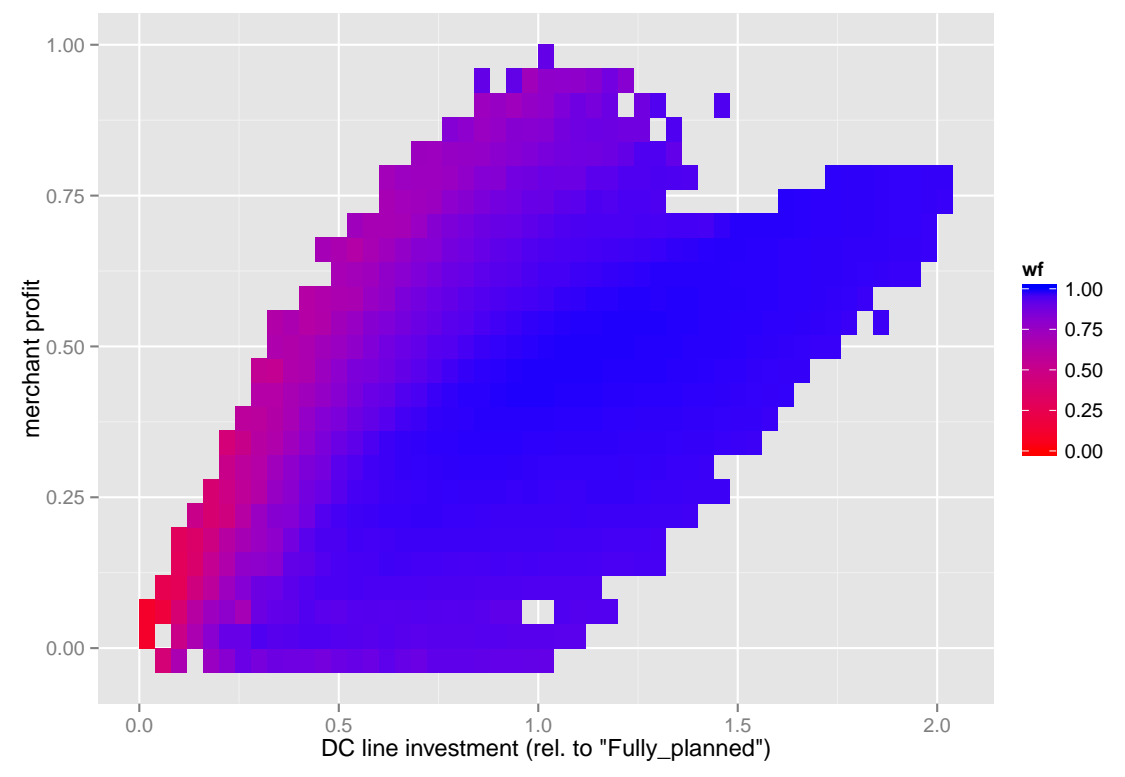

Figure 4: Unit welfare contribution (wf) and unit merchant profit for different investment choices under SRMC pricing. 


\begin{tabular}{|c|c|c|}
\hline & WF contribution & profit-share of WF-contribution \\
\hline Stackelberg-LRMC & $84.48 \%$ & $96.05 \%$ \\
Stackelberg-SRMC & $90.85 \%$ & $171.49 \%$ \\
\hline
\end{tabular}

Table 5: Welfare contribution and merchant profit share of that welfare contribution in the Stackelberg scenarios.

\begin{tabular}{|l|c|c|c|}
\hline$[\mathrm{mn} €$ p.a. $]$ & Generation cost & AC Expansion cost & DC Expansion cost \\
\hline AC Only & 17729.98 & 200.99 & - \\
Stackelberg-LRMC & 17070.31 & 219.04 & 9.79 \\
Stackelberg-SRMC & 17063.72 & 160.26 & 27.56 \\
Fully Planned & 17038.03 & 117.66 & 27.40 \\
\hline
\end{tabular}

Table 6: Costs of all scenarios, under both LRMC and SRMC pricing in mn $€$ p.a. Transmission expansion costs are annuities.

However, as with the Stackelberg cases, the more severe findings emerge from analyzing distributional aspects: In Figures 5 and 6, the indicator displays the unit changes to generator, AC transmission and consumer rents, relative to the Fully Planned case, and unit merchant profit. In many of the cases, which still represent profitable investment cases from a merchant perspective, the welfare gain that accrues to the group of any party except the merchant investor(s) is $\leq 50 \%$ of the improvement delivered by the optimal, Fully Planned solution. In some cases under SRMC pricing, rents of generators, consumers and regulated transmissions are significantly lower than in the AC Only case: Then, those parties do, in aggregate, lose rents that are then collected by the merchant investor. This was already observed in the SRMC-Stackelberg case, corresponding to a high level of DC investment expenditure. 


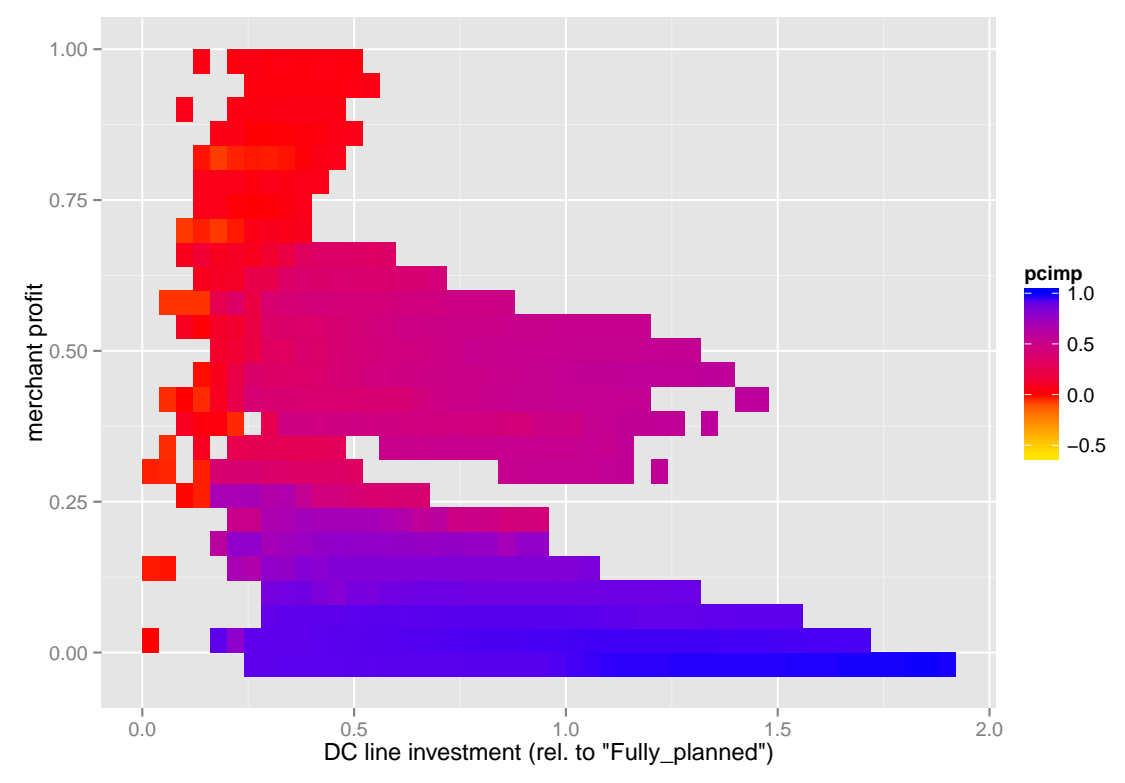

Figure 5: Unit rent increase of generators+consumers (pcimp) and unit merchant profit for different investment choices under LRMC pricing.

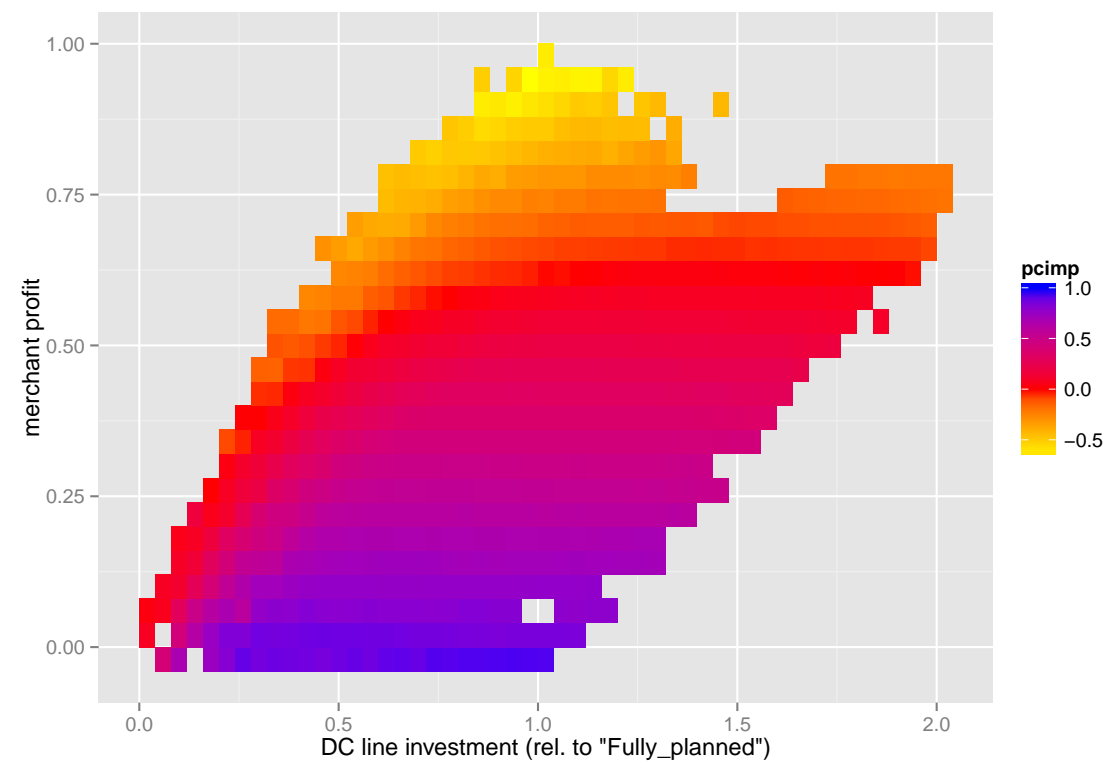

Figure 6: Unit rent increase of generators+consumers (pcimp) and unit merchant profit for different investment choices under SRMC pricing. 


\section{Conclusion}

In our analysis, merchant investment can, from an overall welfare perspective, lead to surprisingly fair results: We obtain $\sim 80-90 \%$ welfare gain as compared to the ideal, Fully Planned case. This seems to hold also for cases where we relax the Stackelberg assumption. However, we find evidence that the welfare losses implied by the merchant investment decisions not only relate to the investment volume, but also the merchant's network structure.

What may matter more is that the distributional effects of merchant transmission investment are quite severe: "The merchant takes it all" may, for some situations, be the correct diagnosis; "all" meaning the overall welfare contribution generated by the merchant's investment choices. Further to that, there are situations where rents accrued by the merchant investor are even higher than the welfare gain induced by the merchant investment. This case is surely one that would make it hard to justify merchant activity, even if regulated (and carefully planned) alternatives are not at hand. Further, these observations illustrate that the idea that (especially short-term) zonal prices could lead to stimulation of sensible infrastructure investment is a fallacy.

Relating those findings to the arguments used in favor of allowing merchant investment, such as high technological risk and difficulties of different jurisdictions/actors to coordinate, implies that even if those arguments apply, merchant investment should be considered with extreme care, as the distributional consequences may be worse than doing nothing at all.

More specifically, relating those findings to the recent developments of technology, governance and realized cross-border interconnector projects in Europe, it seems that little space is left for allowing merchant interconnectors to play any serious role: Technology (HVDC connections, often subsea) is more mature than it was in the 1990s, and it seems to be sufficiently well understood by both regulators and network companies. Additionally, the numerous DC-interconnector projects realized since the nineties, especially in the Baltic Sea region, are encouraging the belief that coordination problems between different jurisdictions can be overcome and are, thusly, not a valid problem. This is consistent with the increasing reluctance of the EC to approve merchant interconnector projects, as observed by Cuomo and Glachant (2012).

Concerning the potentially severe distributional effect of interconnector investment, the existence of inter-regulatory agreements, which do presumably also cover rent-sharing issues, gives some hope that regulators are able to cope with these aspects and that gains from trade can be distributed in accordance with political objectives.

\section{Acknowledgment}

The authors thank Christian von Hirschhausen and Daniel Huppmann for valuable comments and support. 


\section{References}

50Hertz, Amprion, TenneT, and TransnetBW (2012): Netzentwicklungsplan Strom 2012, 2. überarbeiteter Entwurf der Übertragungsnetzbetreiber, URL: http://www. netzentwicklungsplan.de/content/netzentwicklungsplan-2012-2-entwurf.

50Hertz, Amprion, TenneT, and TransnetBW (2013a): Bericht der deutschen Übertragungsnetzbetreiber zur Leistungsbilanz 2013 nach EnWG $§ 12$ Abs. 4 und 5, 50Hertz and Amprion and TenneT and TransnetBW, URL: http://www.bmwi.de/BMWi/Redaktion/PDF/J-L/leistungsbilanzbericht-2013, property=pdf, bereich=bmwi2012, sprache=de, rwb=true.pdf.

50Hertz, Amprion, TenneT, and TransnetBW (2013b): Netzentwicklungsplan Strom 2013, 2. Entwurf der Übertragungsnetzbetreiber, URL: http://www . netzentwicklungsplan. de/content/netzentwicklungsplan-2013-erster-entwurf.

Askheim, L. O. (2012): Developers' objectives and NRA decisions: NorGer HVDC, URL: http://www.eui.eu/Projects/FSR/Documents/Presentations/Energy/ 2012/120127Exemptions/120127AskheimLars0lav.pdf.

BNetzA (2010): Bundesnetzagentur gives green light to the first direct current interconnector to Norway, URL: http://www.bundesnetzagentur.de/SharedDocs/ Pressemitteilungen/EN/2010/101125DirectCurrentInterconnectorNorway . html?nn=193356.

Brunekreeft, G. (2004): Market-based investment in electricity transmission networks: controllable flow, Utilities Policy 12(4):269-281.

Brunekreeft, G. (2005): Regulatory issues in merchant transmission investment, Electricity Transmission Electricity Transmission 13(2):175-186.

Brunekreeft, G. and Newbery, D. (2006): Should merchant transmission investment be subject to a must-offer provision?, Journal of Regulatory Economics 30(3):233-260.

Buijs, P. and Belmans, R. (2012): Transmission Investments in a Multilateral Context, Power Systems, IEEE Transactions on 27(1):475-483.

CESI (2009): Working Group "Electricity interconnections". Phase II: methodology for the assessment of new infrastructures and application to the assessment of the interconnection projects already identified in the Baltic area., CESI, URL: http://ec.europa.eu/energy/infrastructure/doc/2009_bemip_ a9017216-interconnections-phase_ii-final-june_2009.pdf.

Cuomo, M. and Glachant, J.-M. (2012): EU Electricity Interconnector Policy: Shedding Some Light on the European Commission's Approach to Exemptions, URL: http://www.florence-school.eu/portal/page/portal/FSR_HOME/ENERGY/ Publications/Policy_Briefs/PB_2012.06_digital.pdf. 
Dijkstra, E. (1959): A note on two problems in connexion with graphs, Numerische Mathematik 1(1):269-271.

Doorman, G. L. and Frøystad, D. M. (2013): The economic impacts of a submarine HVDC interconnection between Norway and Great Britain, Energy Policy 60:334-344.

EC (2005): EXEMPTION DECISION NO. E/2005/001, ESTLINK PROJECT, URL: http://ec.europa.eu/energy/infrastructure/exemptions/doc/doc/ electricity/2005_estlink_decision_en.pdf.

EC (2007): Exemption decision on the BritNed interconnector, URL: http: //ec.europa.eu/energy/infrastructure/exemptions/doc/doc/electricity/ 2007_britned_decision_en.pdf.

EC (2008): Exemption decision on the East-West Cable project, URL: http: //ec.europa.eu/energy/infrastructure/exemptions/doc/doc/electricity/ 2008_east_west_cable_decision_uk_en.pdf.

EC (2009a): Baltic Energy Market Interconnection Plan (BEMIP), URL: http://ec. europa.eu/energy/infrastructure/bemip_en.htm.

EC (2009b): Commission staff working document on Article 22 of Directive 2003/55/EC concerning common rules for the internal market in natural gas and Article 7 of Regulation (EC) No 1228/2003 on conditions for access to the network for crossborder exchanges in electricity, EC, Brussels, URL: http://ec.europa.eu/energy/ infrastructure/infrastructure/gas/doc/sec_2009-642.pdf.

EC (2009c): Regulation (EC) No 714/2009 of the European Parliament and of the Council of 13 July 2009 on conditions for access to the network for cross-border exchanges in electricity and repealing Regulation (EC) No 1228/2003, URL: http://eur-lex. europa.eu/LexUriServ/LexUriServ.do?uri=CELEX : 32009R0714: EN : NOT.

EC (2010): Ausnahmegenehmigung der Energie-Control Kommission gemäß Artikel 7 der Verordnung (EG) Nr. 1228/2003 für Eneco Valcanale S.r.l., URL: http://ec.europa.eu/energy/infrastructure/exemptions/doc/doc/ electricity/2010_arnoldstein_travisio_decision_de.pdf.

EC (2012): Baltic Energy Market Interconnection Plan 4th progress report, URL: http://ec.europa.eu/energy/infrastructure/doc/20121016_4rd_bemip_ progress_report_final.pdf

Egerer, J., Kunz, F., and Hirschhausen, C. v. (2013): Development scenarios for the North and Baltic Seas Grid - A welfare economic analysis, Utilities Policy 27(0):123-134.

ENTSO-E (2011): ENTSO-E Grid Map, ENTSO-E, Brussels, URL: https : //www . entsoe. eu/resources/grid-map/. 
ENTSO-E (2012a): 10-Year Network Development Plan 2012, ENTSO-E, Brüssel, URL: https://www.entsoe.eu/system-development/tyndp/tyndp-2012/.

ENTSO-E (2012b): Regional Investment Plan Baltic Sea, ENTSO-E, Brussels, URL: https://www.entsoe.eu/system-development/tyndp/tyndp-2012/.

ENTSO-E (2012c): Scenario Outlook \& Adequacy Forecast 2012-2030, ENTSO-E, Brussels, URL: https://www.entsoe.eu/system-development/ system-adequacy-and-market-modeling/soaf-2012-2030/.

ENTSO-E (2013): Consumption Data, URL: https://www.entsoe.eu/data/ data-portal/consumption/.

ESPON (2010): ReRisk - Regions at Risk of Energy Poverty, ESPON, Luxembourg, PV und Wind Potential: S. 226 ff., URL: http://www.espon.eu/export/sites/default/ Documents/Projects/AppliedResearch/ReRISK/ReRiskfinalreport.pdf

Gabriel, S. A. and Leuthold, F. U. (2010): Solving discretely-constrained MPEC problems with applications in electric power markets, Energy Economics 32(1):3-14.

Gans, J. S. and King, S. P. (2004): Access Holidays and the Timing of Infrastructure Investment, Economic Record 80(248):89-100.

Gately, D. (1974): Sharing the Gains from Regional Cooperation: A Game Theoretic Application to Planning Investment in Electric Power, International Economic Review 15(1):195-208.

Green, R., Staffell, I., and Vasilakos, N. (2011): Divide and conquer? Assessing k-means clustering of demand data in simulations of the British electricity system., URL: http://www.upo.es/eps/troncoso/Citas/IDEAL07/CitaIDEAL07-3.pdf.

Hansen, D. F.-P. (2012): TPA and Unbundling Exemptions, Bundesnetzagentur, Fiesole, URL: http://www.energy-regulators.eu/portal/page/portal/ FSR_HOME/ENERGY/Policy_Events/Workshops/2012/TPA\%20and\%20Unbundling\% 20Exemptions/120127_Hansen.pdf.

de Hauteclocque, A. and Rious, V. (2011): Reconsidering the European regulation of merchant transmission investment in light of the third energy package: The role of dominant generators, Energy Policy 39(11):7068-7077.

International Energy Agency and Organisation for Economic Co-operation and Development (2011): World energy outlook 2011, IEA, International Energy Agency : OECD, Paris.

Joskow, P. and Tirole, J. (2005): Merchant Transmission Investment, Journal of Industrial Economics 53(2):233-264. 
Joskow, P. (2005): Patterns of Transmission Investment, Faculty of Economics, University of Cambridge, URL: http://www.econ.cam.ac.uk/electricity/publications/wp/ ep78.pdf.

Knops, H. and De Jong, H. (2005): Merchant interconnectors in the European electricity system, Journal of Network Industries 6:261-292.

Kristiansen, T. and Rosellón, J. (2010): Merchant electricity transmission expansion: A European case study, Energy 35(10):4107-4115.

Kuijlaars, K.-J. and Zwart, G. (2003): Regulatory Issues Surrounding Merchant Interconnection, In: Conference on Methods to Regulate Unbundled Transmission and Distribution Business on Electricity Markets, Stockholm, URL: http://www.marketdesign. se/images/uploads/2003/cp_061603_2_zwart_kuijlaars.pdf.

Leuthold, F., Weigt, H., and von Hirschhausen, C. (2012): A Large-Scale Spatial Optimization Model of the European Electricity Market, Networks and Spatial Economics 12(1):75-107.

Littlechild, S. (2012): Merchant and regulated transmission: theory, evidence and policy, Journal of Regulatory Economics 42(3):308-335.

Mann, J. (2013): Financing transmission - a third way?, URL: http://www.eprg.group cam.ac.uk/wp-content/uploads/2013/05/Mann.pdf

Nylund, H. (2012): Regional cost sharing in expansions of electricity transmission grids, working Paper.

PLATTS (2011): World Electric Power Plants Database, URL: http://www •platts .com/ Products/worldelectricpowerplantsdatabase.

R Core Team (2013): R: A Language and Environment for Statistical Computing, URL: http://www.R-project.org/

Schweppe, F. C., Caramanis, R. D., Tabors, M. C., and Bohn, R. E. (1988): Spot Pricing of Electricity, Kluwer, Boston.

Stigler, H. and Todem, C. (2005): Optimization of the Austrian Electricity Sector (Control Zone of VERBUND APG) by Nodal Pricing, Central European Journal of Operations Research 13(2):105-125.

Svenska Kraftnät and 50Hertz (2014): Press Release: Swedish-German cooperation on electricity connection: Hansa PowerBrigde, URL: http://www.50hertz.com/de/file/ 140328_Press_Release_Hansa_PowerBridge.pdf.

SvK (2011): Idag införs elområden - Svenska Kraftnät, URL: http://svk.se/Press/ Nyheter/Nyheter-pressmeddelanden/Allmant/Idag-infors-elomraden/. 
Tangerås, T. P. (2012): Optimal transmission regulation of an integrated energy market, Energy Economics 34(5):1644-1655.

Taylor, J. and Hover, F. (2011): Linear Relaxations for Transmission System Planning, Power Systems, IEEE Transactions on 26(4):2533-2538.

Teusch, J., Behrens, A., and Egenhofer, C. (2012): The Benefits of Investing in Electricity Transmission: Lessons from Northern Europe, CEPS - The Centre for European Policy Studies, URL: http://www.ceps.eu/ceps/dld/6542/pdf.

Turvey, R. (2006): Interconnector economics, Energy Policy 34(13):1457-1472. 


\section{A. Nomenclature}

\section{Sets}

$b z$

$l$

lm

$l r$

$n$

$s$

$t$

\section{Parameters}

$B_{l}$

$C_{s}$

$D_{n, t}$

$\operatorname{Exp}_{l}$

$\overline{\operatorname{Exp}}_{l}$

$F_{l}^{\max }$

$I_{l}$

$\operatorname{Inc}_{l, n}$

$M_{l}^{\zeta}$

$Q_{s, n}^{\max }$

Slack $_{n}$

\section{Variables}

$\delta_{n, t}$

$\zeta_{l r, t}$

$\zeta_{l m, t}$

$\exp _{l}$

$p_{n, t}$

$p D_{l m, t}$

$q_{s, b z, t}$
Bidding zone

Lines in the electric grid

Subset of $l$, merchant lines

Subset of $l$, regulated lines

Node

Power plant technology

Hour

Line susceptance

Marginal production cost of plant type $s$

Demand at node $n$ in $t$

Initial line expansion level

Maximum expansion level of line $l$

Thermal limit of existing line $l$

Investment cost per MW on line $l$

Incidence matrix

Upper bound on zeta-flows

Maximum generation of plant $s$ at node $n$

Slack bus

Phase angle

Flows through endogenously added AC lines

Flows through DC lines

Expansion on line $l$

price at node $n$ in $t$

Price difference on merchant lines in $t$

Generation of plant $s$ in bidding zone $b z$ in $t$ 


\section{B. Background on Merchant Interconnectors in Europe}

Investments in electricity grid infrastructure, as well as increased competition, are an important element in the development of the internal energy market that the European Commission (EC) seeks to promote. EC regulation 714/2009 (EC, 2009c) allows exemptions from certain aspects of the regulation for investments in cross-border lines in order to stimulate investments that would not occur due to excessively high risk were exemptions not in place. When building electricity grids, costs are generally sunk and not recoverable. The risks potential investors face may include a change in the cost and revenue structure, as described in $(\mathrm{EC}, 2009 \mathrm{~b})$. This might be caused by regulatory uncertainty, especially when more than one regulator is involved or when technological risk is high. Therefore a potential investor may be allowed an exemption from parts of existing regulation.

A full exemption frees the interconnector from the obligation to third party access and enables the owner to set fees and tariffs that are used to earn revenues through congestion rents. Equivalently, the owner might be able to withhold capacity in order to increase the congestion rents.

These exemptions may be granted by the National Regulatory Authorities (NRAs) for a limited time and are reviewed by the European Commission if more than one Member State is involved in granting the exemption following amongst other things these rules:

- the investment needs to increase competition;

- the risk involved necessitates the exemption; and

- the exemption must not hinder the functioning of the internal market and the regulated system.

An analysis of the four exemption decisions by the EC since 2005 is conducted by Cuomo and Glachant (2012). The authors observe a recent tightening of the exemption regime by not granting full exemptions and imposing additional requirements on cross-border interconnector development. The EC has made decisions for the following cases:

- Estlink, a 350 MW HVDC cable between Estonia and Finland, commissioned in 2006

- BritNed, a 1 GW HVDC cable connecting the British and Dutch grids, commissioned 2011

- East-West Cable One, a 350 MW HVDC cable connecting Great Britain and Ireland, delayed; and

- Arnoldstein/Tarvisio, a 132 kV, 160 MW AC line between Austria and Italy, commissioned 2012.

The decision by the NRAs allowing EstLink an exemption from tariff regulation and third party access was confirmed by the EC in 2005 (EC, 2005). For BritNed, the 
exemption was approved in 2007, but due to concerns regarding a possible undersizing of the interconnector's capacity, the obligation to present a financial report 10 years into the interconnector's operation was added. If the revenues were to exceed the expectations, the NRA could introduce a profit cap or require BritNed to increase capacity (which would not be covered by the exemption) in order to reduce congestion rents EC (2007). The exemption for the East-West Cable was confirmed by the EC in 2009 as the risk involved in the project was deemed sufficient due to the planned competing regulated $500 \mathrm{MW}$ interconnector EirGrid (EC, 2008). The approval was linked to the commissioning of EirGrid and also included conditions regarding congestion management and trading. The project is currently delayed. The EC decided in 2010 that the exemption for the AC overhead interconnector Arnoldstein-Tarvisio would be granted, but no exemption from third party access would be given. Furthermore all increases in capacity had to be approved by the EC (EC, 2010).

Furthermore NorGer KS, the company in charge of the development of the NorGer cable between Norway and Germany, applied in March 2010 for an exemption for 25 years and full capacity of the planned cable $(1,400 \mathrm{MW})$. The project fulfilled the requirements of being a new interconnector between states (Norway being on a par with Member States (Hansen, 2012)), expected enhancement of competition, investment risk and no harmful effects to the market according to the German regulatory authority BNetzA. The exemption was granted by BNetzA in 2010 (BNetzA, 2010). Because the EC's risk assessment showed that the interconnector might still be built without exemption and Norway's preference for a regulated interconnector, NorGer KS withdrew the application in April 2011 (Askheim, 2012).

\section{Flow limits due to Network Topology}

The following considerations are inspired by Taylor and Hover (2011).

Step \#1. A power flow $f_{l}$ on a line $l$, connecting nodes 1 and 2 , with voltage angles $\delta_{1}, \delta_{2}$ respectively, line series susceptance $B_{l}$ and constrained by the ampacity-based flow limit $F_{\max , l}$ is subject to the following relations:

$$
\begin{gathered}
\left|f_{l}=B_{l}\left(\delta_{1}-\delta_{2}\right)\right| \leq F_{\max , l} \\
\Rightarrow \quad\left|\delta_{1}-\delta_{2}\right| \leq \frac{1}{B_{l}} F_{\max }
\end{gathered}
$$

If we now assume a continuous line expansion such that the new line has now $\Delta$ times of its original susceptance and ampacity (17) still holds true:

$$
\begin{aligned}
& \left|f_{l}=\Delta B_{l}\left(\delta_{1}-\delta_{2}\right)\right| \leq \Delta F_{\max , l} \\
\Rightarrow & \left|\delta_{1}-\delta_{2}\right| \leq \frac{\Delta 1}{\Delta B_{l}} F_{\max , l}
\end{aligned}
$$


Thus, $(16)=19$ and we have a limit on angle-differences along lines that is independent of the expansion factor $\Delta$ of the line, but only depends on its physical characteristics.

Step \#2. Further to that, DCLF requires that the sum of angle differences summed up along each closed mesh is 0 . This is illustrated in Figure 7, which depicts a sample meshed network. It immediately follows that

$$
0=\left(\delta_{2}-\delta_{1}\right)+\left(\delta_{3}-\delta_{2}\right)+\left(\delta_{4}-\delta_{3}\right)+\left(\delta_{5}-\delta_{4}\right)+\left(\delta_{1}-\delta_{5}\right) .
$$

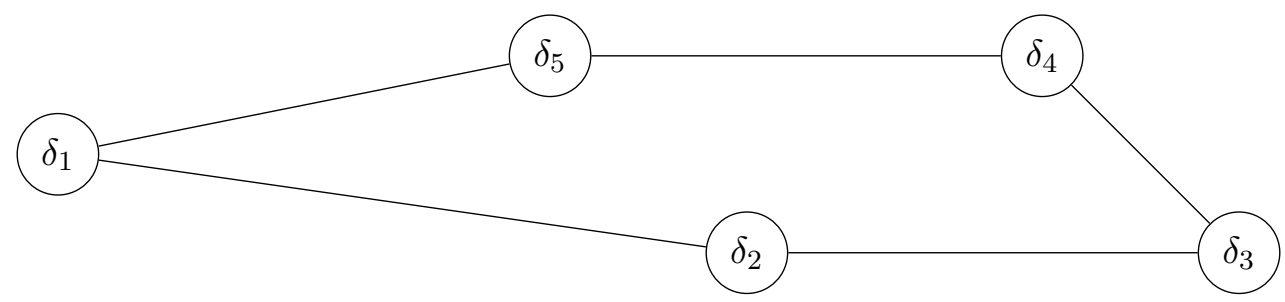

Figure 7: Sample meshed network

Nodes $n$ labeled with their respective voltage angle $\delta_{n}$. Source: Own depiction.

However, as we see in Step \#1, the angle differences along each line $l$ are subject to a general limit that emerges from the physical line characteristics 19 , independent of any level of line expansion. As (20) must hold, (19) is not necessarily sufficient: Any angle difference on a line $l$ is constrained by the shortest path of voltage-angle difference limits. Therefore, 19) can, without any loss of generality, be replaced by

$$
\left|\delta_{1}-\delta_{2}\right| \leq \min \left\{M_{\zeta, \mathrm{sp}, l}, F_{\max , l}\right\} B_{l}^{-1},
$$

where $M_{\zeta, \mathrm{sp}, l}$ is the shortest path between nodes 1 and 2 , measured by the sum of maximum angle difference limits. I.e. (21) is a valid constraint on line angle differences, independent of network expansion state, but only depending on physical characteristics of the line itself and on network topology. $M_{\zeta, \mathrm{sp}, l}$ can thus be calculated by a shortest-path algorithm, such as the Dijkstra-algorithm (Dijkstra, 1959). 


\section{Identification of Reference Hours}

Due to limits in computational power, it is not feasible to calculate the MPEC for, e.g. a full year of 8760 hours. However, due to the periodicity of load and, partly, intermittent renewables feed-in, we use reference hours. The approach to use reference hours, or reference cases is widespread in modeling. However, identifying the reference cases is often done by using the modeler's intuition. In order to formalize this process, we apply a so-called k-means clustering process to the data, as e.g. Green et al. (2011) propose: We group the hours into $N$ groups such that in-group variance is smallest. The data we use here is two-dimensional: We have electric load and intermittent feed-in (Wind and PV). The clustering process is done using $\mathrm{R}$ Core Team (2013). Figure 8 shows the result of the clustering process for $N=6$. The resulting clusters are not necessarily of the same

\section{k-Means Identification of cases}

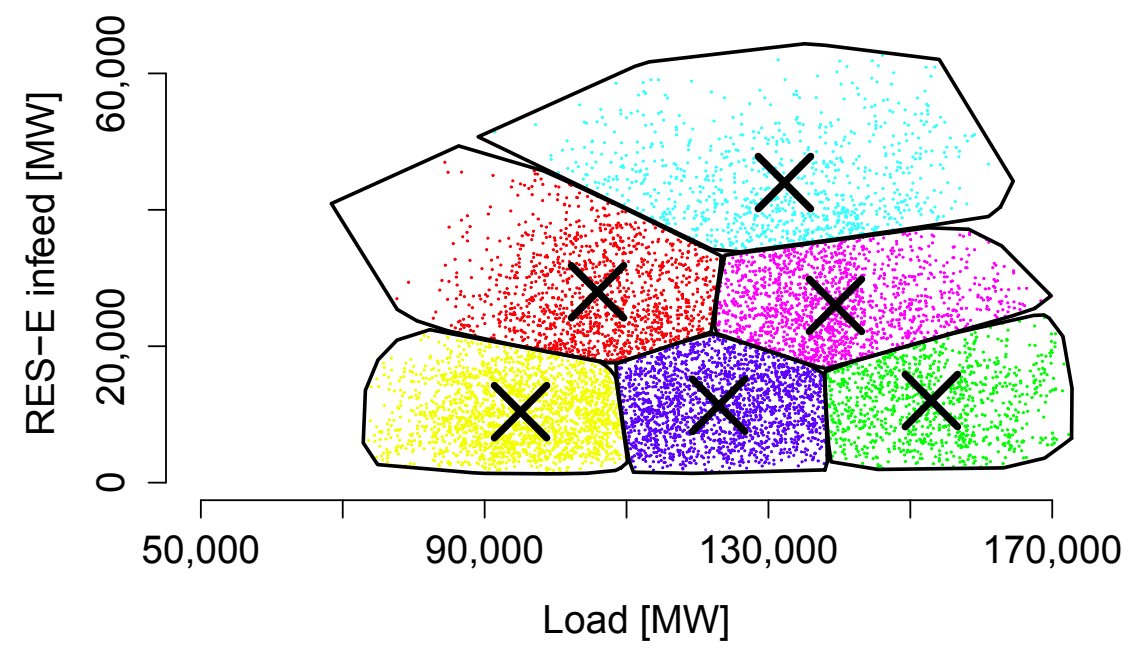

Figure 8: Identification of Reference Hours.

Cluster Centers are located at the crosses. Source: Own Calculations.

size; therefore, we take into account the cluster size as a relative weight for the respective reference hours. 


\section{E. Tables}

Table 7: Rents and costs, in $m n €$ p.a.; investment costs are the respective annuities.

\begin{tabular}{|c|c|c|c|c|c|c|c|}
\hline & \multicolumn{4}{|c|}{ Rents } & \multicolumn{3}{|c|}{ Costs } \\
\hline & Producers & Consumers & $\begin{array}{l}\text { AC con- } \\
\text { gestion }\end{array}$ & $\begin{array}{l}\text { DC con- } \\
\text { gestion }\end{array}$ & $\begin{array}{l}\mathrm{DC} \\
\text { invest- } \\
\text { ment }\end{array}$ & $\begin{array}{l}\text { AC } \\
\text { invest- } \\
\text { ment }\end{array}$ & Generation \\
\hline \multicolumn{8}{|l|}{ LRMC pricing } \\
\hline$A C$ Only & 15236.36 & 120968.17 & 1185.29 & 0.00 & 0.00 & 200.99 & 17729.98 \\
\hline Stackelberg & 14876.62 & 121401.63 & 1136.49 & 606.90 & 9.79 & 219.04 & 17070.31 \\
\hline Fully Planned & 24097.23 & 113987.55 & 33.77 & 19.15 & 27.40 & 117.66 & 17038.03 \\
\hline \multicolumn{8}{|l|}{ SRMC pricing } \\
\hline$A C$ Only & 10767.39 & 125463.73 & 1158.69 & 0.00 & 0.00 & 200.99 & 17729.98 \\
\hline Stackelberg & 12540.61 & 124128.56 & 234.90 & 1165.17 & 27.56 & 160.26 & 17063.72 \\
\hline Fully Planned & 12666.30 & 124388.61 & 572.71 & 510.07 & 27.40 & 117.66 & 17038.03 \\
\hline
\end{tabular}

